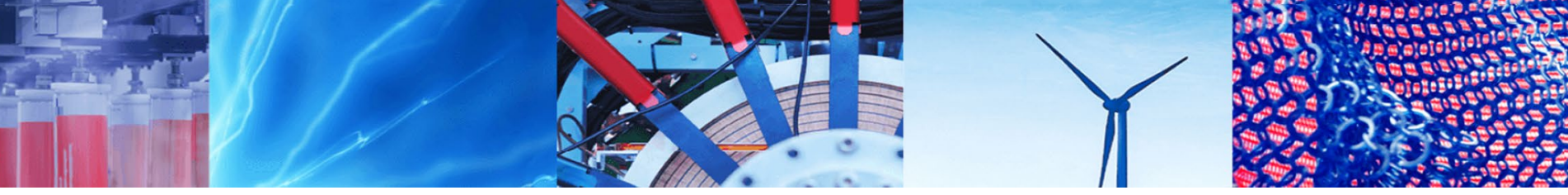

Research Article

\title{
Investigation of hydrocolloid for ice pattern preparation with extrusion 3D printing
}

\author{
Hong-Jun Liu ${ }^{1}$ (D J Jun-Hong Wang ${ }^{1} \cdot$ Dai-Fa Lin $^{1} \cdot$ Ya-Min Li ${ }^{1} \cdot$ Yatskovskyi Dmytro ${ }^{1}$
}

Received: 30 October 2021 / Accepted: 3 February 2022

Published online: 04 March 2022

(c) The Author(s) 2022 OPEN

\begin{abstract}
Various 3D printing processes have been used to fabricate sacrificial patterns replacing wax patterns of investment casting, which significantly reduces the costs and lead times associated with single part or small batch production. Compared to polymer patterns, 3D printed ice patterns are cheaper and cleaner and are easily removed without mold cracking and other issues. In the present study, the hydrocolloid was developed for ice pattern preparation with extrusion 3D printing. The xanthan gum has a perfect thickening effect on hydrocolloids containing starch. When the xanthan gum content is $5 \%$, the hydrocolloid has good self-stable behavior, which ensures extrudates have a minimal spreading effect. After freeze-drying and heating up to $500^{\circ} \mathrm{C}$, the hydrocolloid can be completely lost without residual ash.
\end{abstract}

\section{Article highlights}

- The hydrocolloids with starch and xanthan gum as a gelling agent were developed for preparing ice pattern with extrusion 3D printing.
- The hydrocolloids with $5 \%$ xanthan gum content have good self-stable behavior and smooth extrusion property.

- The ice pattern can be completely lost when heated above $500^{\circ} \mathrm{C}$.

Keywords 3D printing $\cdot$ Investment casting $\cdot$ Ice pattern $\cdot$ Extrusion $\cdot$ Hydrocolloid $\cdot$ Xanthan gum

\section{Introduction}

Investment casting (IC) is well known for producing complex and precise casting products [1,2]. The traditional IC process builds shell mold by wax pattern preparation, slurry coating, stuccoing and dewaxing. It is a time-consuming and costly process, mainly in the tooling making for wax pattern, especially when its shape is complicated. 3D printing, also called Rapid Prototyping, Additive Manufacturing, provides a cost-effective mean to rapidly fabricate complex sacrificial IC patterns without hard tooling [3-5]. Many 3D printing processes have been applied to the fabrication of sacrificial patterns, including stereolithography (SLA), selective laser sintering (SLS), and fused deposition modeling (FDM). The 3D printed sacrificial patterns can result in a significant reduction in the cost and lead time associated with single part or small batch production, so the IC process combined with $3 \mathrm{D}$ printing is also called rapid investment casting. The feasibility was assessed by applying sacrificial patterns fabricated by FDM $[6,7]$, Model Maker II [8], and an indirect method based on silicone rubber tooling [9] to produce metal castings. The results showed the cost and lead time savings and

Hong-Jun Liu, hongjun_liu@hotmail.com | 'State Key Laboratory of Advanced Processing and Recycling of Non-Ferrous Metals, Lanzhou University of Technology, 287 Langongping Road, Lanzhou 730050, Gansu, China. 
relatively accurate final castings with acceptable surface quality.

In the IC process of replacing wax patterns with webbed SLA patterns, shell mold cracking may be problematic during SLA pattern burnout. This problem can be solved by optimizing the internal web structure and improving the burnout process of SLA patterns through numerical simulations and experimental observations $[10,11]$. It is found that the hexagonal web structure has less thermal stress than the square or triangular web structures [12]. The fracture of shell mold can be avoided by buckling and craze fracture of the webbed patterns in the early burnout stages [13]. SLS technology can fabricate sacrificed patterns with wax [14, 15], polystyrene (PS) [16], high impact polystyrene (HIPS) [17], eucalyptus/polyethersulfone (PES) blend [18]. These materials are generally thermoplastic and have low thermal strength and excellent yieldability. The shell mold cracking is not a serious problem, but the burnout process of the sacrificial pattern must be strictly controlled. FDM uses various polymers as printing materials, thereunder the evidence that these materials can be melted and burned out from the shell mold without detrimental effects. Because the surface finish of the final castings greatly depends upon the finishing quality of the FDM patterns, many investigations have been done on the surface improvement techniques for FDM patterns and the effects on the castings [19-22].

Though various polymer materials are successfully applied to prepare sacrificial patterns with 3D printing, there are still some problems and technical difficulties, including pattern expansion, shell mold cracking, and environmental pollution. When the sacrificial patterns are made of ice, the above issues are expected to be overcome. A 3D printing process known as rapid freeze prototyping was developed to prepare ice patterns for the IC process [23-25]. The ice patterns can be generated by selective depositing water layer by layer in a low-temperature environment in two ways: drop-on-demand deposition and continuous deposition [26]. In the dropon-demand deposition, water is ejected drop by drop, while in the continuous deposition, water is continuously extruded from a nozzle. The drop-on-demand deposition method fabricated ice patterns with pure water or distilled water mixed with dye, which has very low viscosity and a spreading effect. Especially, enough waiting time between two successive layers is needed to prevent heat accumulation and uneven spreading of water. So the fabrication efficiency is affected, and the process control becomes more complicated. The drop-on-demand deposition is suitable for the fabrication of small volume or shell ice patterns.

The extrusion 3D printing processes produce 3D solid objects using layer-by-layer extrudable materials with selfsupporting ability, which have the advantages of flexibility in processing and handling, ease, and low cost in equipment and software building. The representative extrusion $3 \mathrm{D}$ printing process is FDM. The ice patterns may also be prepared in the way of a continuous deposition by extrusion 3D printing process. We can use the hydrocolloid with high viscosity and shear-thinning property as the extrudable material; the extrudates have no obvious spreading effect due to the good self-supporting ability. In a freezing environment, the prepared layers can maintain the supporting capacity without deformation before freezing. The hydrocolloid suitable for extrusion deposition is the prerequisite for the ice pattern preparation. However, the literature review revealed that there is a lack of investigation on the extrudable hydrocolloid for ice pattern preparation, so the research work presented in this paper focused on the development of hydrocolloid and its performance evaluation.

\section{Experimental}

\subsection{Materials}

The hydrocolloids were prepared from 1 to $5 \mathrm{wt} \%$ of xanthan gum (Shandong Fufeng Fermentation Co., Ltd.), 5 wt\% of starch (Tianjin Zhiyuan Chemical Reagent Co., Ltd.), 2 wt\% of glycerol (Tianjin Baishi Chemical Reagent Co., Ltd.) and the remaining deionized water. Under magnetic stirring, starch and glycerol were dissolved in deionized water in a $150 \mathrm{ml}$ beaker, which was placed in a water bath at $60{ }^{\circ} \mathrm{C}$. The xanthan gum was then added to the suspension and stirred for $30 \mathrm{~min}$. Then, the hydrocolloid was prepared by keeping the beaker containing the mixture in a water bath at $80^{\circ} \mathrm{C}$ for $15 \mathrm{~min}$.

\subsection{Rheological properties}

Rheological property of hydrocolloid was measured using an NDJ-8S rotational rheometer (Shanghai Fangrui Instrument Co. Ltd.) with the 4\# rotor, which had an effective working region of a cylindrical surface with a diameter of Ф $3 \mathrm{~mm}$ and a length of $30 \mathrm{~mm}$. The apparent viscosity was measured at a constant shear rate of $30 \mathrm{r} / \mathrm{min}$ with $5 \mathrm{~min}$ pre-shearing to ensure the viscosity measurement in the linear viscoelastic region. The temperature of the hydrocolloid was set at $20^{\circ} \mathrm{C}$ during viscosity measurement. The viscosity value was the average of three measurements.

\subsection{Printability}

The schematic diagram of the extrusion 3D printing equipment is shown in Fig. 1. The hydrocolloid was loaded into a $5 \mathrm{~mL}$ syringe. The loaded syringe was then mounted 


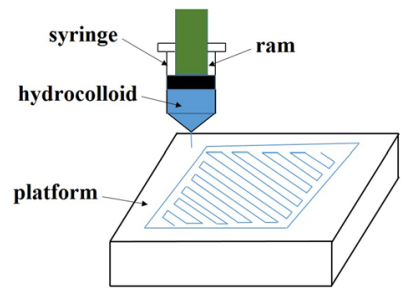

Fig. 1 Schematic diagram of the extrusion 3D printing

on a custom 3-axis positioning system equipped with a ram extruder. The 3D printing equipment was placed in a freezer at $-18^{\circ} \mathrm{C}$, but the temperature of the syringe containing the hydrocolloid needed to be controlled at about $20^{\circ} \mathrm{C}$ with a heat jacket. The hydrocolloid was extruded from a nozzle with an inner diameter of $0.86 \mathrm{~mm}$, and the print speed of extrudates was $11 \mathrm{~mm} / \mathrm{s}$. The extrudates were deposited onto a platform. In the 3D printing process, the layer height should be set smaller than the inner diameter of the nozzle, so the extrudates can be bonded to the printed hydrocolloid without exerting too much pressure on the lower layers. The tests showed that it was appropriate to set the layer height to about 0.8 times the inner diameter of the nozzle, which was $0.7 \mathrm{~mm}$. A square spiral pattern was used to observe the printability of the hydrocolloids, as shown in Fig. 2. Good printability means smooth extrusion process, regular printed pattern and extrudate's uniform width.

\subsection{D printing}

In order to check the formability of hydrocolloid in 3D printing, validation tests were performed. Before printing tests, the CAD model was designed and then converted to STL format. G-codes were automatically generated through the data processing of STL file in 3D printing software. The hydrocolloid with $5 \%$ xanthan gum was extruded from a nozzle which moved according to G-codes. Ice patterns were fabricated by stacking the extrudates layer by layer at $\mathrm{a}-18^{\circ} \mathrm{C}$ environment.

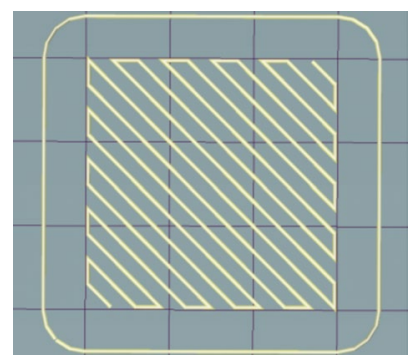

Fig. 2 Square spiral pattern for printability test

\subsection{Disposal of ice pattern}

As the sacrificial pattern of the IC process, the ice pattern should be coated by ceramic slurry by gel-casting process at a temperature slightly below zero and then deeply frozen. After freeze-drying and high-temperature sintering, the ice pattern is lost, and the shell mold is ready for casting. Therefore, the disposal of ice mold should go through two stages: freeze-drying and high-temperature burnout. To investigate the dehydration and thermal decomposition characteristics of ice pattern, a $\Phi 10 \mathrm{~mm} \times 5 \mathrm{~mm}$ specimen was printed for weight loss analysis. The specimen was dehydrated by a freeze-dryer at $-58^{\circ} \mathrm{C}$ and $10 \mathrm{~Pa}$, and the weight loss with time was measured. Five specimens were prepared for each composition of the hydrocolloids, and the weight loss was measured at 4th, 6th, 12th, 24th, and 36th hours, respectively. $20 \mathrm{mg}$ sample was taken from a freeze-dried specimen of hydrocolloid with $5 \%$ xanthan gum content, and a TG analysis was performed with Netzsch ST A449F3 thermal analyzer at a heating rate of $10^{\circ} \mathrm{C} / \mathrm{min}$ and air flow rate of $100 \mathrm{~mL} / \mathrm{min}$. TG and DTG curves were used to analyze the characteristic decomposition temperature of dehydrated ice pattern.

\section{Experimental results and discussions}

\subsection{Rheological behavior of hydrocolloids}

The rheological curves of hydrocolloids with varying compositions are shown in Fig. 3. At the same shear rate, the viscosity of the hydrocolloid decreases with the increase in xanthan gum content, which is more obvious at a low shear rate. As the shear rate is $1.5 \mathrm{r} / \mathrm{min}$, the viscosity of the

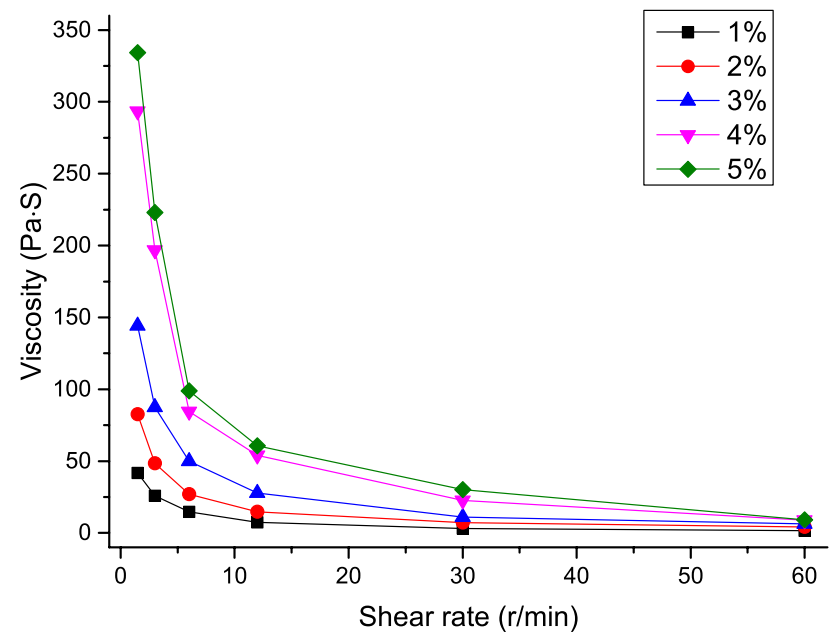

Fig. 3 Rheological behaviors of hydrocolloids with varying xanthan gum contents 
Table 1 The numerical values computed for both $n$ and $K$ in Eq. 1

\begin{tabular}{lllllc}
\hline $\begin{array}{l}\text { Xanthan gum } \\
\text { content }\end{array}$ & $1 \%$ & $2 \%$ & $3 \%$ & $4 \%$ & $5 \%$ \\
\hline$n$ & 0.213 & 0.193 & 0.218 & 0.184 & 0.201 \\
$K$ & 58.3 & 115.2 & 199.9 & 418.4 & 474.3 \\
\hline
\end{tabular}

hydrocolloid with $5 \%$ xanthan gum content significantly increases by up to one order of magnitude than that of the hydrocolloid with $3 \%$ xanthan gum content. The viscosity of the same hydrocolloid decreases with the increase in the shear rate. The higher the xanthan gum content in hydrocolloids, the more significant the decrease in the viscosity. When the xanthan gum content is $5 \%$, the viscosity of hydrocolloid decreases by nearly two orders when the shear rate increases from 1.5 to $60 \mathrm{r} / \mathrm{min}$. This shear-thinning behavior can be quantified by fitting the apparent viscosity vs shear rate curves using standard power law flow model of the form:

$\eta=K \dot{\gamma}^{n-1}$

where $\eta$ is the apparent viscosity, $\dot{\gamma}$ is the shear rate, $K$ is the consistency index, and $n$ is the flow index.

Table 1 summarizes the numerical values computed for both $n$ and $K$. For a shear-thinning fluid: $0<n<1$. The more the shear-thinning of the hydrocolloid, the closer $n$ is to 0 . As shown from Table 1, $n$ values range from 0.184 to 0.218 , which are far less than 1 and close to 0 , so the hydrocolloids have strong shear-thinning behavior.

The shear-thinning behavior is important to facilitate the extrusion of hydrocolloid. When the hydrocolloid passes through the nozzle, the shear rate increases sharply, and the viscosity becomes very low so that it can be extruded very easily. After the extrudate is deposited, there is no shear effect, and the viscosity becomes very high so that the ice pattern can maintain its shape without collapse. However, for the hydrocolloids with a xanthan gum content of less than $3 \%$, shear-thinning has little effect on extrusion formability because the viscosity at a low shear rate is too low to support the weight of extrudates.

The xanthan gum is a high molecular heteropolysaccharide composed of three different monosaccharides (D-mannose, D-glucose, and D-glucuronic acid). Due to the repulsion between negative charges, hydrogen bonds cannot be formed in the molecule, and the molecular chain is relatively stretched. Therefore, it is easy to interact with starch molecules to form hydrogen bonds, increasing the entanglement points between molecular chains. The molecular entanglement of xanthan gum and starch molecules increases the viscosity of the system and the viscous resistance to flow. Therefore, xanthan gum has a very good thickening effect on hydrocolloid. When the xanthan gum content is high enough, the hydrocolloid has a high viscosity, obvious shear-thinning behavior, and good extrusion property.

\subsection{Printability of hydrocolloids}

A series of extrusion and deposition tests for hydrocolloids were performed using the square spiral pattern in Fig. 2. Figure 4 shows the representative patterns printed with the hydrocolloids with varying xanthan gum contents. The xanthan gum content has a significant effect on the printability of hydrocolloid. It was observed that the hydrocolloid with $1 \%$ xanthan gum did not possess sufficiently high viscosity and solid-like behavior to enable the printing of self-stable extrudates. Due to the low viscosity, the extrudates still had obvious flow behavior and formed an irregular printing pattern. When the hydrocolloids with $2 \%$ or $3 \%$ xanthan gum were used for printing, clearer patterns were printed. However, the self-stable ability of the
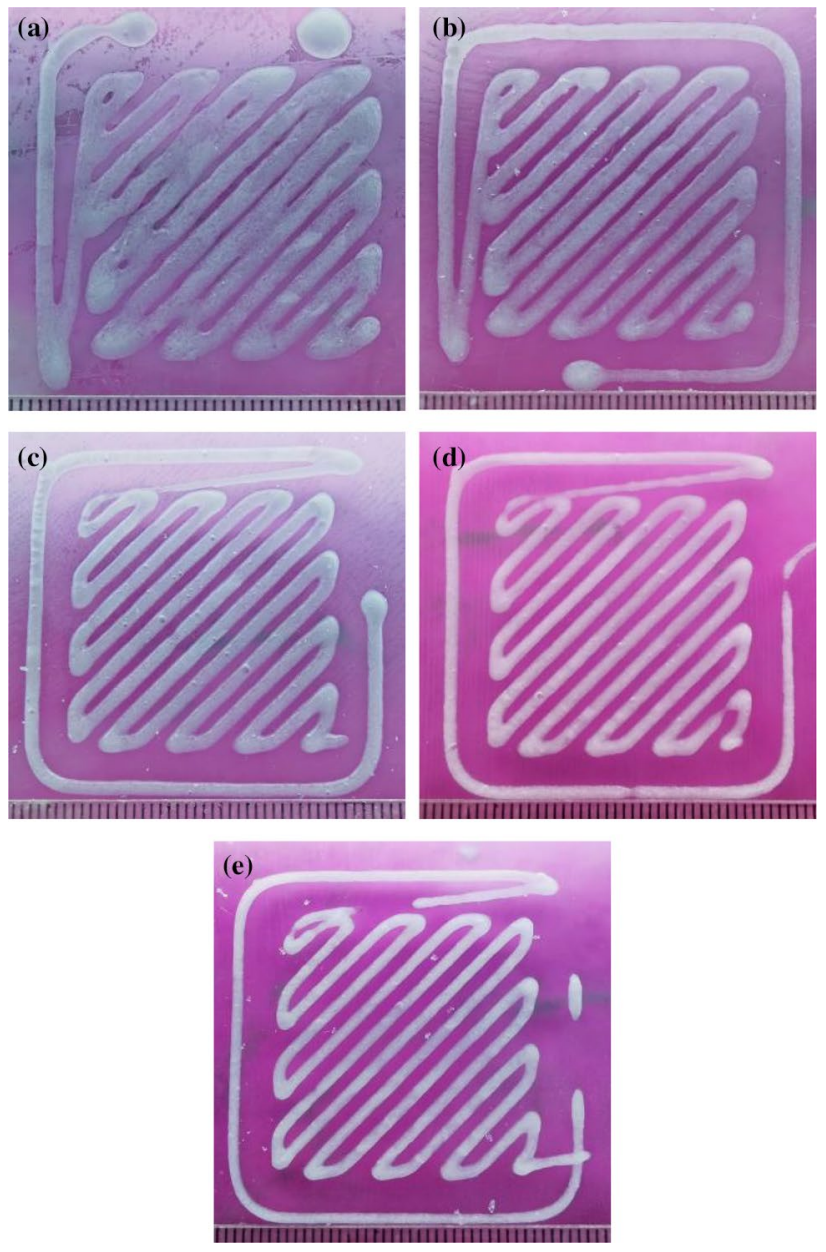

Fig. 4 Square spiral patterns printed by hydrocolloids with varying xanthan gum contents. a $1 \%$; b $2 \%$; c $3 \%$; d $4 \%$; e $5 \%$ 
extrudates was still poor. The extrudates spread slightly on the platform and had a width much larger than the inner diameter of the nozzle. When xanthan gum contents in hydrocolloids were $4 \%$ or $5 \%$, the solid-like extrudates enabled the patterns to be printed clearly and accurately. According to the printability experiments, the hydrocolloids with xanthan gum less than $4 \%$ cannot be used for ice pattern printing. When xanthan gum content was higher than 5\%, the hydrocolloid was too thick, and the extrusion became less smooth, and the phenomenon of extrusion breaking was observed frequently.

The hydrocolloids with $4 \%$ or $5 \%$ xanthan gum have smooth extrusion behavior and the extrudates with a uniform width, which can be used for preparing ice pattern with 3D printing process. In comparison, the hydrocolloid with $5 \%$ xanthan gum has a more accurate profile in the sharp corner transition position, and the width of the extrudate is closer to the inner diameter of the nozzle, so it is more suitable for printing high-quality ice pattern.

\subsection{D printing tests}

Figure $5 \mathrm{a}-\mathrm{c}$ shows the $\mathrm{CAD}$ model, 3D printing process, and printed ice pattern of a cone part, which had a maximum diameter of $20 \mathrm{~mm}$ and a maximum height of $15 \mathrm{~mm}$. The result reveals that the hydrocolloid with $5 \%$ xanthan gum has good self-stable behavior, and the ice pattern has an exact shape. The extrudates can be deposited on the previous layer without deforming the stacked part. It noticed that even parts with a certain slope (maximum inclination angle of $25^{\circ}$ in this part) could be printed without supports.

To check the repeatability of the 3D printing process, the ice patterns with various shapes were prepared. Figure 6 a shows an ice pattern of the cylinder and its printing process. The design dimension of the cylinder is $\Phi 20 \mathrm{~mm} \times 7 \mathrm{~mm}$ with a wall thickness of $4 \mathrm{~mm}$. The $3 \mathrm{D}$ printing process of hydrocolloid is smooth, and the ice pattern is completely printed with a straight contour line and no obvious deformation. However, the printing effect of the inner hole is slightly worse. This is due to the poorer heat dissipation for the latent heat released during the freezing process of the hydrocolloid in the inner hole. The dimension measurement of this ice pattern shows that the average diameter error is $0.08 \mathrm{~mm}$ (the error range -0.02 to $0.2 \mathrm{~mm}$ ), and the average height error is $0.02 \mathrm{~mm}$ (the error range -0.12 to $0.22 \mathrm{~mm}$ ). The size of the ice pattern is slightly larger than the design size, which is caused by the expansion of the extrudate during the deposition and freezing process.
Fig. 5 CAD model, 3D printing process, and ice pattern of the cone part. a CAD model; $\mathbf{b} 3 \mathrm{D}$ printing process; c prepared ice pattern
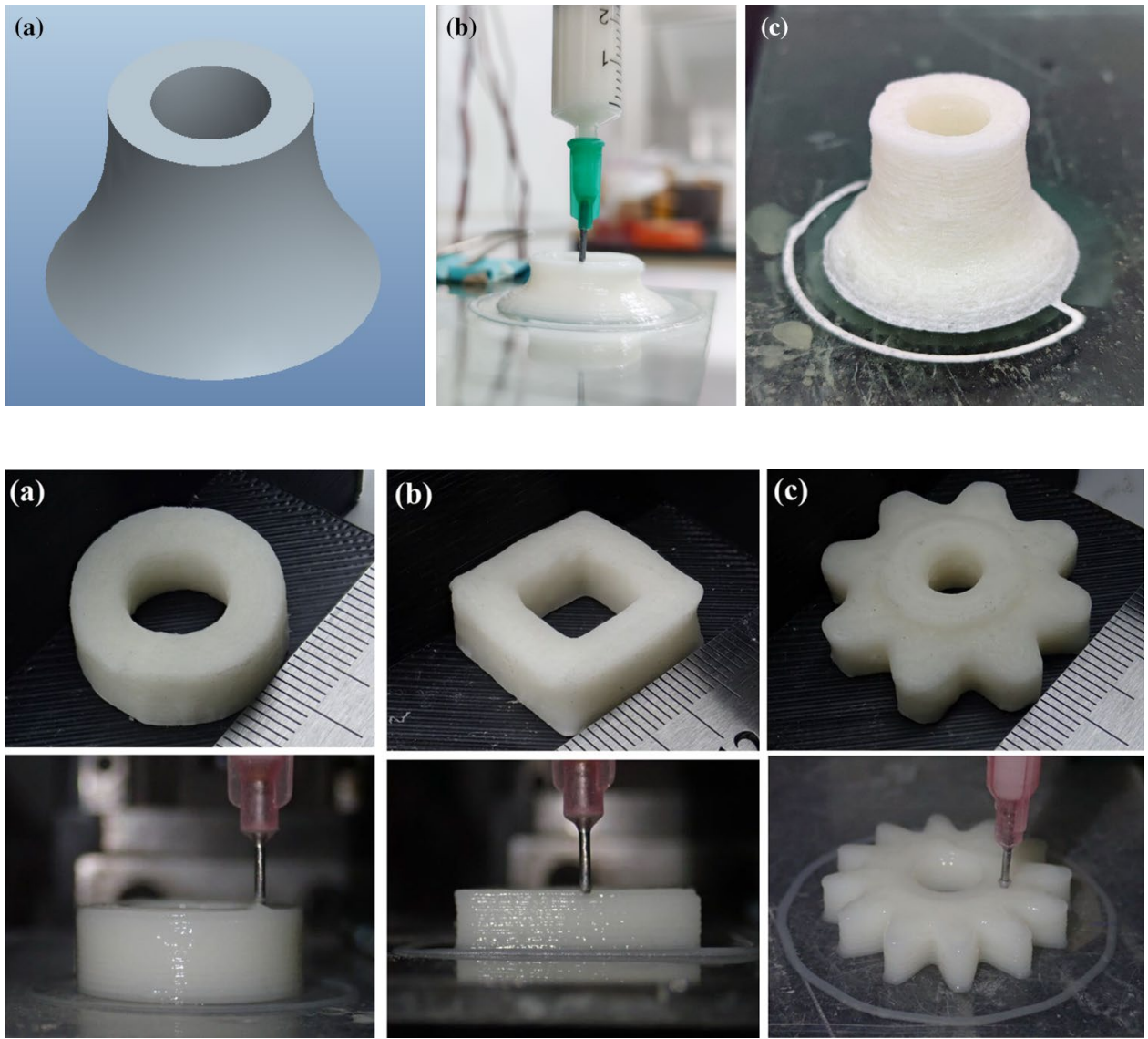

SN Applied Sciences A SPRINGER NATURE journal 
Figure $6 \mathrm{~b}$ and $\mathrm{c}$ shows the ice patterns of the box shape (the side length $20 \mathrm{~mm}$, the height $7 \mathrm{~mm}$, and the wall thickness $4 \mathrm{~mm}$ ) and the gear shape (the addendum circle $30 \mathrm{~mm}$, the dedendum circle $20 \mathrm{~mm}$ and the height $7 \mathrm{~mm}$ ). The printing effect is acceptable, and the ice patterns are clear and complete. Different from a cylinder, there are some sharp turnings in the trajectory curves in each layer. It can be seen that there are extra extrudates at the turning positions. This is an inevitable problem in ram extrusion 3D printing: the extrusion of non-Newtonian fluid cannot respond in real-time to the movement of the ram, and the extrudate always has a little lag behind the theoretical extrusion requirements. These two parts also have the problem of a poorer printing effect in the inner hole due to the release of latent heat. For the box shape ice pattern, the average side length error is $0.26 \mathrm{~mm}$ (the error range -0.42 to $0.54 \mathrm{~mm}$ ), and the average height error is $0.13 \mathrm{~mm}$ (the error range -0.04 to $0.26 \mathrm{~mm}$ ). For the gear shape ice pattern, the average addendum circle error is $0.15 \mathrm{~mm}$ (the error range -0.58 to $0.62 \mathrm{~mm}$ ), and the average height error is $0.18 \mathrm{~mm}$ (the error range -0.14 to $0.38 \mathrm{~mm}$ ).

The above 3D printing tests show that the hydrocolloid developed in this paper has the capability of preparing ice patterns with extrusion 3D printing.

\subsection{Disposal process of ice pattern}

The weight loss curve for frozen specimen during freezedrying is shown in Fig. 7. The weight of the specimen decreases monotonically with freeze-drying time, as expected. The weight decreases sharply in the first 6 drying hours and then becomes slower. At the beginning of drying, the free water in the hydrocolloid is rapidly sublimated, which reduces the weight of the specimen. When most free water is sublimated, the weight of the specimen

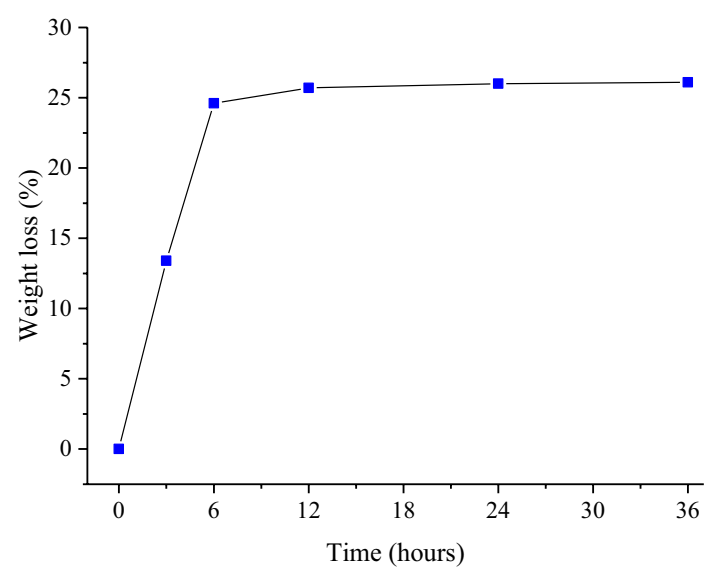

Fig. 7 Weight loss curve of frozen specimen during freeze-drying changes little. Then, even if the temperature rises above zero, the starch and xanthan gum in the hydrocolloid can maintain their molecular network, and the specimen will not collapse. This process takes about $6 \mathrm{~h}$. It takes a long time for a thick or large specimen and a shorter time for a thin or small specimen.

Adding xanthan gum can make more water molecules form adsorbed water in hydrocolloids. Moreover, because the trisaccharide side chain of xanthan gum is closely aligned with the main chain, it can better form a close and firm three-dimensional network structure with starch molecular chain segments so as to prevent the loss of water molecules through sublimation. Therefore, it will take a long time to remove most of the water in the frozen hydrocolloid.

The TG and TGA curves of the freeze-dried specimen are shown in Fig. 8. When the temperature rises from 30 to $228^{\circ} \mathrm{C}$, there is a wide valley on the DTG curve and obvious weight loss (43.9\%) on the corresponding TG curve. This is due to the loss of adsorbed water and volatile substances in the molecular network of xanthan gum and starch. In the temperature range of $228-367^{\circ} \mathrm{C}$, the TG curve shows a weight loss of $34.6 \%$, and the TGA curve shows obvious weight change. At this stage, the specimen is degraded by thermal oxidation. Most molecular chains in xanthan gum and starch are destroyed. The escape of degraded products leads to weight loss. Due to the difference in bond stability of main chains and branch chains, the pyrolysis goes on in the temperature range of about $140^{\circ} \mathrm{C}$. However, some molecular chains cannot be degraded into escaping small molecules but carbonized directly. The pyrolysis carbon reacts with oxygen in the air at a temperature range of $367-499^{\circ} \mathrm{C}$ to produce carbon dioxide or carbon monoxide, resulting in a weight loss of $19.7 \%$. From 500 to $1000^{\circ} \mathrm{C}$, the weight loss of the specimen is tiny, and the

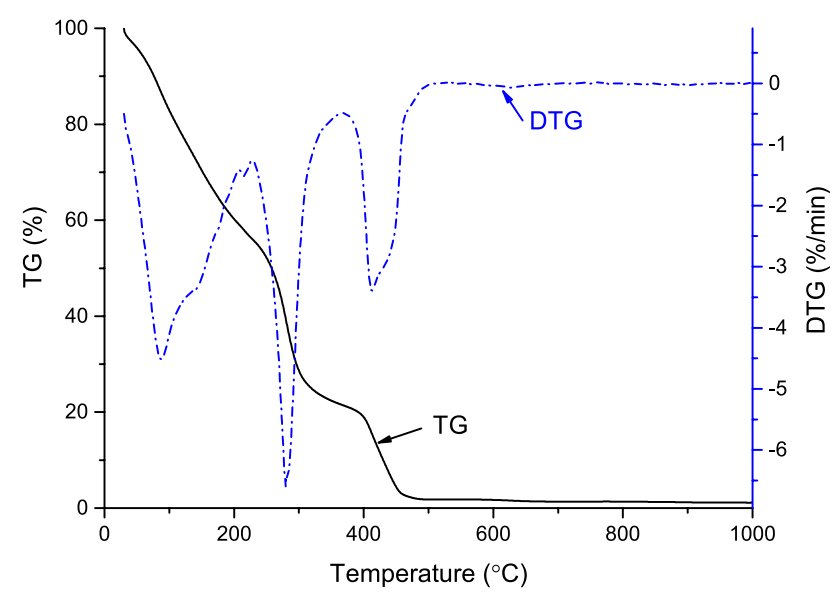

Fig. 8 TG and DTG curves of a freeze-dried specimen 
residue is some inorganic additives in starch and xanthan gum, about $1-2 \%$ of freeze-dried specimen.

Therefore, the hydrocolloid used for ice pattern preparation can be completely burnout after freeze-drying and heating up to $500{ }^{\circ} \mathrm{C}$, similar to the loss of wax pattern in the traditional investment casting process.

\section{Conclusions}

This study can be concluded by the following remarks:

(1) The hydrocolloids with starch and xanthan gum as gelling agents show a shear-thinning behavior suitable for extrusion. From the printing tests of 2D pattern and 3D parts, good printability has been observed for hydrocolloid with $5 \%$ xanthan gum.

(2) The TG test suggests the ice pattern should be heated above $500{ }^{\circ} \mathrm{C}$ to be completely lost. Before that, the ice pattern should be dehydrated by freeze-drying.

(3) The hydrocolloid is suitable for ice pattern preparation with extrusion 3D printing and has the potential application in the investment casting process.

Funding This work was supported by the National Natural Science Foundation of China (52062029) and the Key Science and Technology Project of Gansu Province of China (18YF1GA064).

\section{Declarations}

Conflict of interest The authors declare no conflict of interest.

Open Access This article is licensed under a Creative Commons Attribution 4.0 International License, which permits use, sharing, adaptation, distribution and reproduction in any medium or format, as long as you give appropriate credit to the original author(s) and the source, provide a link to the Creative Commons licence, and indicate if changes were made. The images or other third party material in this article are included in the article's Creative Commons licence, unless indicated otherwise in a credit line to the material. If material is not included in the article's Creative Commons licence and your intended use is not permitted by statutory regulation or exceeds the permitted use, you will need to obtain permission directly from the copyright holder. To view a copy of this licence, visit http://creativecommons. org/licenses/by/4.0/.

\section{References}

1. Pattnaik S, Karunakar DB, Jha PK (2012) Developments in investment casting process - a review. J Mater Process Technol 212(11):2332-2348

2. Jones $S$, Yuan C (2003) Advances in shell moulding for investment casting. J Mater Process Technol 135(2):258-265
3. Cheah CM, Chua CK, Lee CW, Feng C, Totong K (2005) Rapid prototyping and tooling techniques: a review of applications for rapid investment casting. Int J Adv Manuf Technol 25:308-320

4. Chhabra M, Singh R (2011) Rapid casting solutions: a review. Rapid Prototyp J 17:328-350

5. Purwar U, Javed MA, Vidya S (2021) A review on research aspects and trends in rapid prototyping and tooling assisted investment casting. Mater Today Proceed 46:6704-6707

6. Lee CW, Chua CK, Cheah CM, Tan LH, Feng C (2004) Rapid investment casting: direct and indirect approaches via fused deposition modeling. Int J Adv Manuf Technol 23(1-2):93-101

7. Kumar P, Ahuja I, Singh R (2012) Application of fusion deposition modelling for rapid investment casting-a review. Int J Mater Eng Innov 3:204-227

8. Chua CK, Feng C, Lee CW, Ang GQ (2005) Rapid investment casting: direct and indirect approaches via model maker II. Int J Adv Manuf Technol 25:26-32

9. Rahmati S, Akbari J, Barati E (2007) Dimensional accuracy analysis of wax patterns created by RTV silicone rubber molding using the Taguchi approach. Rapid Prototyp J 13:115-122

10. Chen X, Li D, Haihua Wu, Tang Y, Zhao L (2011) Analysis of ceramic shell cracking in stereolithography-based rapid casting of turbine blade. Int J Adv Manuf Technol 55:447-455

11. Zhou J, Zhongliang Lu, Miao K, Ji Z, Dong Y, Li D (2015) Quick fabrication of aeronautical complicated structural parts based on stereolithography. Propuls Power Res 4(2):63-71

12. Yao WL, Leu MC (2000) Analysis and design of internal web structure of laser stereolithography patterns for investment casting. Mater Des 21(2):101-109

13. Ferreira JC, Mateus A (2003) A numerical and experimental study of fracture in RP stereolithography patterns and ceramic shells for investment casting. J Mater Process Technol 134(1):135-144

14. Wang DH, Dong AP, Zhu GL et al (2019) Rapid casting of complex impeller based on 3D printing wax mold and simulation optimization. Int J Adv Manuf Technol 100(9-12):2629-2635

15. Qian X, Zhang Y, Yin Y, Zhou J, Shen X, Ji X (2019) Optimization on the deformation of circular bosses of a compressor casing wax pattern in selective laser sintering process. Procedia Manuf 37:578-583

16. Özer G, Özbay B, Öter ZÇ et al (2020) Investigation of the surface quality and dimensional accuracy of polymer molds produced by selective laser sintering (SLS) method for investment casting (IC). Int J Cast Metals Res 33(2-3):146-152

17. Yang JS, Shi YS, Shen QW et al (2009) Selective laser sintering of HIPS and investment casting technology. J Mater Process Technol 209(4):1901-1908

18. Jiang K, Guo Y, Bourell DL, Zeng W, Li Z (2013) Study on selective laser sintering of eucalyptus/PES blend and investment casting technology. Procedia CIRP 6:510-514

19. Singh $R$, Singh $S$, Kapoor $P$ (2016) Investigating the surface roughness of implant prepared by combining fused deposition modeling and investment casting. J Process Mech Eng 230(5):403-410

20. Singha J, Singhb R, Singhc $H$ (2018) Surface roughness prediction using Buckingham`s Pi-theorem for SS-316L hip implant prepared as rapid investment casting. Mater Today Proceed 5(9):18080-18088

21. Singha D, Singhb R, Boparaic KS (2018) Development and surface improvement of FDM pattern based investment casting of biomedical implants: a state of art review. J Manuf Process 31:80-95

22. Kumara P, Singhb R, Ahujaa IPS (2015) Investigations on dimensional accuracy of the components prepared by hybrid investment casting. J Manuf Process 20:525-533

23. Ming Q, Leu MC, Richards VL, Schmitt SM (2004) Dimensional accuracy and surface roughness of rapid freeze prototyping ice patterns and investment casting metal parts. Int J Adv Manuf Technol 24:485-495 
24. Zhang W, Leu MC, Feng C, Ren R, Zhang R et al (2000) Investment casting with ice patterns made by rapid freeze prototyping, In: Proceedings of the 11th Annual Solid Freeform Fabrication Symposium, University of Taxas at Austin, Austin, TX, USA, 66-72

25. Zhang W, Leu MC, Ji Z, Yan Y (1999) Rapid freezing prototyping with water. Mater Des 20:139-145

26. Liu Q, Sui G, Leu MC (2002) Experimental study on the ice pattern fabrication for the investment casting by rapid freeze prototyping. Comput Ind 48:181-197
Publisher's Note Springer Nature remains neutral with regard to jurisdictional claims in published maps and institutional affiliations.

\section{SN Applied Sciences}

